\title{
Snapshots of a Changing Scholarly Communications Environment
}

\author{
by DAVID C. PROSSER
}

\begin{abstract}
Almost two years after the formation of SPARC Europe, the LIBER pre-conference seminar in St Petersburg gave an excellent opportunity to review progress on the road to achieving the aims of SPARC Europe. The traditional models of scholarly communication are increasingly being shown to be antiquated and insufficiently flexible to adapt to the new environment. SPARC Europe calls for far reaching changes in the way we approach scholarly communications. The talks in the seminar provide snapshots of the changing environment. They highlight the activities being taken at all levels by a wide variety of stakeholders in the scholarly communications process: Small and society publishers are developing alternatives to inflexible and restrictive 'Big Deals'; funding bodies and research organisations worldwide are becoming aware of issues surrounding scholarly communication; institutional repositories are providing new communications channels; and libraries are investigating new directions and taking on new roles. This paper will expand on some of these recent developments.
\end{abstract}

\section{A CHANGING ENVIRONMENT}

SPARC Europe was created in 2002 following the successful launch in 1998 of SPARC. SPARC, an initiative of the Association of Research Libraries (ARL) in the US, was created as a positive response to the problems libraries faced in ensuring continued access to the latest research literature. The problems regarding access to STM (Scientific, Technical, and Medical) journals were particularly acute. Year-on-year journal price rises, often in double figures and well above inflation, had for two decades outstripped increases in library budgets. Libraries had to cancel journals in increasing numbers, so reducing the range of titles their researchers had access to. SPARC's remit was to encourage partnerships between libraries, academics, learned societies, and responsible publishers to work to reverse this decline. The focus was initially on cheaper rivals to expensive subscription journals, but over the years the focus has expanded to take in open access initiatives.[1]

While SPARC was always an international organisation, there was felt to be a need for a European equivalent to address some of the unique issues of the European market. Hence SPARC Europe which has continued the work of SPARC in promoting open access as a 
solution to the access / affordability problem and has worked at both the local and political level to promote new communication models, fight damaging publisher mergers and market consolidations, etc.

The past two years have seen significant changes in the scholarly communications environment, with increasing resistance to the old models and greater experimentation with new ideas. The SPARC Europe pre-conference seminar at the 2004 LIBER Annual General Meeting explored some of these changes, charted the changing environment, and looked forward to future developments.

\section{BIG DEALS AND FAIR DEALS}

One of the major changes in the way journals are sold and purchased following the introduction of the Internet has been the development of bundles packages, often referred to as the 'Big Deal'. This has proved to be one of the most controversial developments amongst librarians over the past decade. Libraries can buy online access to an increased proportion of a publisher's journals rather than purchasing subscriptions to a fraction of their titles in print. This made 'Big Deals' initially attractive to the librarians as they provided an immediate increase in the amount of the content available for a limited increase in price. However, while the price per journal (and per article) can drop significantly, invariably the total cost to a library for a publisher's 'Big Deal' will be greater than what the library would have initially been paying to that publisher. This puts additional strain on the library budget. Additionally, while 'Big Deals' often come as multi-year contracts (3-5 years typically) and contain caps on price increases during the period, many also come with strict limits on cancellation of titles during the term of the agreement. This has led to resentment amongst some librarians as they feel they are paying for content that their users do not want.

The tying-up of significant proportions of flat or declining library budgets on 'Big Deals' has led to a potential problem for smaller publishers. Even with 'moderate' annual price increases for 'Big Deals', the restrictions on cancellations mean that an increasing proportion of the library budget is diverted towards the 'Big Deals', leaving an ever decreasing proportion for journals that are not part of the Deals - i.e., journals from small, often society-run publishers. This has been described as the 'Big Squeeze' (Prosser, 2004).

Heather Joseph, President of BioOne, described how many small to mid-sized not-forprofit publishers (who have traditionally published high quality material at low cost) are coming under increasing pressure to sell or license their content to commercial interests. Unfortunately, where this has happened in the past there have often been substantially higher prices for the library market. 
As an alternative to the 'commercialisation' of their titles some smaller publishers, recognising the value of the 'strength in numbers' approach, have come together to form bundled collections. These 'fair deals' have a number of features that mark them as distinct from 'Big Deals':

- They tend to be subject specific rather than publisher specific (e.g., BioOne with 70+ titles in biosciences, Project MUSE with 250+ titles in the arts and humanities, and Project Euclid with 30 plus titles in mathematics.

- Participation is limited to not-for-profit publishers.

- Collaboration with the library community - on governance, operational, and advisory levels - is seen by the publishers as being essential.

- There are no requirements for multi-year commitments - the librarians choose the time frame for subscription.

- There are no restrictions on cancellations, allowing greater flexibility to the libraries.

- $\quad$ Print purchase is decoupled from electronic purchase.

However, while there are many philosophical and operational differences between commercially run 'Big Deals' and non-profit 'Fair Deals' the single largest difference is cost . This difference is seen in both average cost per journal and the total costs for the full packages. The average cost per journal in the BioOne collection is less than $\$ 190$, in contrast with a cost of $\$ 1,300$ per title averaged across all of the ISI-ranked biological science titles. For total costs, the average 2003 expenditure on Elsevier products by ARL libraries was approximately $\$ 1.3$ million - compared to an average expenditure on BioOne of less than $\$ 8,000$.

Obviously, the primary concern for any library will be how well individual titles in a bundle match the needs of the researchers both in terms of subject area and quality. However, libraries may well wish to consider carefully the mission and philosophy behind the bundle, the participants, the licensing terms and conditions, and the price. Libraries can directly affect the direction of the market through their purchasing decisions.

A growing number of libraries, especially in the US, have decided that the 'Big Deals' are no longer attractive as the problems of tying-up increasing proportions of the library budget and reducing flexibility in the libraries' acquisition decisions outweigh the advantages.[2] Resistance to the old, established models is growing as libraries demand greater value for money (in terms of quality, not just quantity) and they wish to support those publishers who have traditionally produced high quality material at reasonable cost. 'Fair Deals' have a vital role to play in ensuring that smaller publishers can bring 
their titles to the 'bundled' market while retaining their business independence independence which may be lost if they were to become part of a 'Big Deal'.

\section{FUNDING BODY SUPPORT FOR OPEN ACCESS}

One of the most encouraging developments in open access over the past two years has been the increasing interest shown at the political and funding body level in the dissemination of the research literature. This has been most dramatically manifest in the UK and US where open access is being discussed within the respective legislatives. In the UK, the House of Commons Science and Technology Committee undertook an extensive inquiry into scientific publishing Like most independent observers the Committee concluded that the current model of scholarly communications is inadequate and recommended a number of steps to promote a more equitable system (Scientific Publications: Free for All? 2004). In particular, the Committee endorsed two recommendations in support of open access put forward by SPARC Europe (amongst others), namely:

- The Research Councils in the UK should require authors to place copies of their papers that result from research funded by the Councils in institutional repositories.

- The Research Councils should make funds available as part of research grants to allow authors to pay publication charges for open access journals.

In the US, Congress is debating endorsing language that would require all authors of papers reporting work funded by the National Institutes of Health (NIH) to deposit copies of the papers in PubMed Central. The NIH is the US Government's largest funding body and it is estimated that this requirement would result in open access to between 50,000 and 60,000 peer-reviewed papers annually.

Within Europe, Germany's Max Planck Gesellschaft (MPG) has played a leading role amongst funding bodies and research organisations in promoting an open access agenda. The MPG is a multi-disciplinary research organisation with 3500 researchers in 80 institutions. Theresa Velden, Executive Director of the Heinz Nixdorf Center for Information Management, described how open access constitutes an essential part of the e-Info programme for the MPG.

In October 2003 at a conference in Berlin initiated by the MPG the Berlin Declaration on Open Access to Knowledge in the Sciences and Humanities was launched to address the lack of institutional commitment to the open access movement. The Berlin Declaration was important as, for the first time, funding bodies and research organisations acknowledged that 'Our mission of disseminating knowledge is only half complete if the information is not more widely and readily available to society.' The institutions realised 
that it is in their interests as funders to support the widest possible dissemination through open access of the research they have funded.

The Berlin initiative has made it clear that open access is a replacement for the current conventional communication paradigm, and not its second class counterpart. As the transition to open access will take time and involve transformations in the traditional library/scholarly information provision system the long-term commitment of funding bodies and research organisations is essential. This is what the Berlin Declaration offers, and it is encouraging that it has been endorsed by so many organisations, both within Germany and beyond As well as all of the major German research organisations, the Declaration has been adopted by, amongst others, the CNRS and INSERM in France, by the FWF Der Wissenschaftsfonds in Austria, the Fonds voor Wetenschappelijk Onderzoek in Flanders, and by CERN (famously, the birthplace of the WWW).

For the MPG signing the Declaration is, however, only the first step in the Berlin process. Regular six-monthly follow-up meetings to discuss progress and map out next steps are planned, with the first of these having taken place in CERN in May 2004. The first follow-up meeting identified a number of positive measures to be taken, including:

\section{General Activity Areas}

- $\quad$ Education and awareness

- Legal issues

- Sustainable technical infrastructure

- $\quad$ Addressing business models

Institutional Measures

- Enforce open access publishing policy on all levels of the organization

- Install steering committee at top executive level

- Create organisational competence centre

- Assign open access policy coordinator

- Ensure long-term funding and guarantee long-term operation

As well as promoting the Berlin process, the MPG offers a model of practical support for open access. The MPG has set up an institutional repository, e-Doc Server, for use by all of its component institutes and containing a wide variety of content (articles, posters, conference papers, $\mathrm{PhD}$ theses, etc.). The repository shows its versatility by not only offering access to papers by MPG authors, but providing a management tool for 
publication data from the institutes - invaluable when producing the obligatory annual report!

The MPG has not neglected open access journal publishingIt is responsible for two Living Review journals. These journals use the power of the Internet to allow authors to up-date their critical reviews as new developments are announced. As the papers are online it is much easier to add references or re-work complete sections than it would be in print. The reviews then become 'living' articles as they develop with the field they are describing. The MPG supports the extension of the Living Reviews journal family to other areas of research and is also developing e-publishing tools and funding online history of science and cultural heritage projects.

The activities of the MPG give us an excellent example of the range of actions that can be undertaken to promote open access: 'moral' support through declarations, advocacy (both within the organisation and externally), practical projects to increase the amount of open access content (both in repositories and journals), and the development of tools to help others make the move to open access. It is to be hoped that many more organisations will sign the Berlin Declaration and follow the positive lead of the MPG.

\section{OPEN ACCESS THROUGH REPOSITORIES}

One of the two routes to open access identified by the Budapest Open Access Initiative (BOAI) is self-archiving in institutional repositories. Authors should deposit copies of their papers (preferably the final version of the papers, after changes to take into account the comments of referees and editors) in online repositories that offer free and unrestricted access over the Internet. These repositories are built to be Open Archive Initiative (OAI) compliant, so allowing the metadata to be 'harvested', facilitating crosssearching.

Stephen Pinfield, Project Director of SHERPA, described two of the problems of the current model of scholarly communications as the 'Impact barrier' and the 'Access barrier'. Impact barriers arise when the wide dissemination that authors desire is restricted by journal subscriptions which limit the number of readers who can read the paper and so limits the authors' impact Access barriers arise when readers, who want easy access to the literature, are restricted by their library's budget constraints to access only a proportion of the literature.

Self-archiving in institutional repositories lowers these barriers. By providing wider dissemination the papers are more visible and will, potentially, be cited more often. This reduces the impact barrier. As readers can now access papers in free, searchable repositories the access barrier is lowered. These are not, however, the only benefits. The 
host institution benefits as free access to its papers raises the profile and prestige of the institution, while providing a means of managing the institution's information assets. For society in general knowledge transfer is increased (as subscription barriers are removed) and education and the public understanding of science are enhanced.

The technological outlay for an institution in setting up a repository is low. A number of free, open source, OAI-compliant software packages exist for managing institutional repositories By constructing OAI-compliant repositories the institution ensures that search engines such as OAIster and even Google will find individual articles and these will not be buried in the 'deep web'.

It has been widely acknowledged that a much greater challenge than the setting-up of a repository is attracting content. The use of repositories is new for many academics and it has (naturally) taken some time for the benefits to be seen widely. Many institutions that have already set up repositories have found it useful to have an institutional policy governing the repository. One of the most noteworthy policies has been that of the Queensland University of Technology in Australia, where "Material which represents the total publicly available research and scholarly output of the University is to be located in the University's digital or E print repository". Material that falls under the policy includes:

- $\quad$ refereed research articles and contributions at the post-print [post-refereed] stage (subject to any necessary agreement with the publisher);

- $\quad$ refereed research literature at the pre-printed [pre-refereed] stage (with corrigenda added subsequently if necessary at the discretion of the author);

- theses;

- $\quad$ un-refereed research literature, conference contributions, chapters in proceedings, etc.

Developing a coherent policy for the institution regarding management of scholarly asserts can help to increase awareness of open access and repositories amongst researchers. A JISC/OSI survey discovered that amongst authors who had never published in an open access journal $77 \%$ did not know anything about repositories. Even amongst authors who were familiar with open access journals and had published in them, $71 \%$ were not aware of repositories (Swan \& Brown, 2004). Interestingly, the same survey discovered that $83 \%$ of authors who had already published in an open access journal and $69 \%$ who had not would willingly deposit their papers in a local repository if required to by their institution or funding body. It would appear that a combination of advocacy to raise awareness and institutional policies would go a long way to ensuring authors deposited their papers within the repositories. 
Institutions can also help in offering assistance to researchers in depositing their papers. In some ways, 'self-archiving' can be a misnomer as it does not have to be the author who actually places the paper in the repository. Some libraries are offering as a service to their researchers the option of having the library deposit the papers. As well as increasing the number of papers deposited (as it reduces an already low barrier to almost zero), it is more likely that library-deposited papers will have greater consistency of metadata than those deposited by the authors.

Within institutions that have set-up repositories a number of common concerns from researchers have been heard. Some authors are worried about the interaction between repositories and publication in peer reviewed journals. They worry that either they will be in breach of copyright if they deposit their paper in the repository or unable to publish in the journal of their choice if a copy of their paper is in the repository. It is true that for some publishers the transfer of copyright from the author means that no version of the paper may appear in an institutional repository. However, these publishers are very much in the minority and a growing proportion is willing to allow some version to appear on the repository An excellent resource for determining publishers' policies is the RoMEo list maintained by the SHERPA project. Of course, it has been noted that the author always has the copyright of the paper until that copyright has been transferred and so can always deposit a copy before signing the copyright transfer form! However, this raised the problem of 'prior publication' and the fear that some journals will not accept papers that have appeared in a repository (or have been presented at a conference). While we do not have an equivalent of the RoMEo list of publishers' attitudes on pre-publication it does appear that the number of publishers who impose a ban on 'prior publication' is diminishing. This is probably partly a result of the arXiv pre-print repository in physics. Almost all papers in high-energy physics appear on arXiv before publication and if journals attempted to enforce a 'no pre-publication' condition they would have no papers to publish!

Some authors are concerned with the possibility of plagiarism and the ease with which their paper could be copied and passed-off as another researcher's work if it is placed in the local repository However, the same tools that allow a paper to be found and plagiarised allow the plagiarism to be detected. As the full-text of the paper is freely available to all it is actually easier to detect plagiarism than it would be if the paper was only available to a limited number of subscribers Other authors are concerned with the increased work-load of depositing papers. The actual time involved (probably no more than 30 minutes at most) is small compared with either writing the paper or doing the research, but is seen as a barrier by some. This is another reason for the library to take on the function of archiving the papers for the authors.

Stephen Pinfield described the efforts within the UK to set up institutional repositories. The major initiative has come from the Joint Information Systems Committee (JISC) which created the FAIR programme of 14 projects to support the disclosure of 
institutional assets. These projects were grouped into a number of clusters covering museums and images, e-prints, e-theses, intellectual property rights, and institutional portals. The whole FAIR programme was funded to the level of $£ 3$ million with each project lasting between 1 and 3 years starting in summer 2002 .

In the area of institutional repositories, one of the FAIR programmes is SHERPA (Securing a Hybrid Environment for Research Preservation and Access). SHERPA has brought together 20 research-led UK universities together with the Arts and Humanities Data Service and British Library in an effort to promote repositories and address a number of issues surrounding them. In particular, SHERPA aimed to have repositories constructed at the participating institutions, to investigate key issues in populating and maintaining e-print collections, to investigate standards-based digital preservation and disseminate learning outcomes and advocacy materials. The project has not offered a centralised solution for repositories, with each partner free to select the repository software and implementation that best suites their needs. However, by providing support and guidance on a number of issues repository provision in the UK is at a high level.

The advantages of national initiatives to promote implementation of institutional repositories were made explicit by Kurt De Belder of the Universiteit van Amsterdam (UvA) in his talk UvA, together with all of the universities in The Netherlands, has set up its own institutional repository under the umbrella of the national Digital Academic Repositories (DARE) project. The UvA repository contains over 60,000 records with over 800 full text documents, covering the full range of scholarly outputs from dissertations, articles, and books, to reports, working papers, etc. Interestingly, they have coupled the online availability of dissertations through the repository with a print on demand service (offered by Amsterdam University Press). Students gain the benefit of wider dissemination of their theses while the Press gains the benefit of online marketing.

The UvA repository shows the direct benefit to researchers of depositing their papers as it offers each researcher a publication list with persistent URLs. Using OpenURLs, the reader is directed from the record in the repository to the full text which may also be in the repository or to the copy in the journal, or to a web-search to find the paper in other versions elsewhere. This drives traffic to the text of the paper, provides more readers and therefore the possibility of greater citations and impact for the author. By offering services of this nature the repository becomes more attractive to authors and they are motivated to deposit their papers in the repository.

By becoming host for an institution's repository the library can play a major part in ensuring the dissemination and preservation of that institution's intellectual wealth. Also, the library becomes the institution's leader on scholarly communications strategy. It is probably no surprise that it is the library community, having suffered the frustrations of the serials crisis over the past decades, that is leading the development of institutional 
repositories and spearheading attempts to create new models for scholarly communications.

\section{NEW DIRECTIONS AND TRENDS FOR UNIVERSITY LIBRARIES}

In a changing electronic environment, libraries have the opportunity to be more than just the collectors and 'hoarders' of objects. The possibility arises for them to initiate a twoway scholarly conversion - fulfilling not only their traditional role of bringing research results into the institution, but also disseminating research from their own institution worldwide. The hosting, development, and management of institutional repositories is just one example of how they might perform this new role. Kurt De Belder gave additional examples and outlined some trends and goals for the library.

The library has been evolving as more and more of the primary literature has gone online. This has led to the development of the 'hybrid' library, but the library can do more than just act as a purchasing department for electronic journals. De Belder noted that as a first stage, libraries organised collections of hyperlinks, leading to separate content/database environments with tied-in services. There was no continuity between the services and no easy way of navigating between them. The second stage is the 'Digital Library', where the library acts as an integration layer between the separate services and offers independent tools and services to access the content and provides the possibility to create personalised environments for readers. The aim is to help the readers navigate through the content in as seamless as way as possible and ensure that they are not stopped and confused by different interfaces and access conditions.

The integrated digital collections and digital library functions can be exported to other environments, such as the electronic learning environment, and used to create personal portals for students and staff. As a consequence the Digital Library content and functions become available in other systems and in fact the library interface disappears in these environments. The goal then becomes the invisible pervasiveness of the library, its services and scientific information. For a library such as that at the UvA, traditional roles and responsibilities have changed as the services offered have extended beyond the physical confines of the library building. A concrete example is the closing and merging of information desks with staff reallocated to provide support to the distant/remote reader at the desktop through an information services back office.

At the heart of the Digital Library is the understanding that digital objects and metadata need to be available for a variety of environments and for re-use and re-purposing. To this end, the raw material (digital object) is placed in "neutral" databases. A metadata layer creates an envelope (resource discovery, technical data, rights management information, processing data, preservation metadata) for complex digital objects. Finally, 
layers of interpretation and presentation are built upon the raw material and the metadata layer. This strategy recognised the importance of a rigorous separation between Digital Library tools and the digital collection itself. As Clifford Lynch has suggested, if we "Think of digital libraries as a collection of tools that make content alive, that help you to find it, that allow you to manipulate it, analyse it, annotate it, comment on it then digital libraries attract, they create, they define a community." (Lynch, 2002)

Another area where the continued development of the Digital Library is important, is in the field of E-science (or cyberscience). This has been defined as "science and research falling under cyber conditions, which - in essence - means science in an environment that is intrinsically geographically non-local and where multiple use and re-use of knowledge objects are the normal situation." (Kircz, 2004). E-science is distinct from electronicbased science. In electronic-based science, ICT is used as a supporting tool enhancing established methodologies and techniques, whereas E-science addresses research issues and applications that only become possible in a fully digital environment.

More and more initiatives are being put together that bring researchers together in a virtual environment and let them share very large data collection, large scale computing researchers, high performance visualization tools, etc. In the UK, the Grid is being developed as an architecture for virtual organisations and 'An infrastructure that enables flexible, secure, coordinated resource sharing among dynamic collections of individuals, institutions and resources.'[3]

As the tools develop within the Digital Library, especially the tools around repositories, the library can take on the role of a digital production centre. Many of the skills and competencies involved with managing an institutional repository (e.g., ensuring material within it is presented to a uniform standard, and enabling the wide discovery and dissemination of the material to an audience outside of the library) are similar to those employed by a traditional journals and monograph publisher. The Library of the UvA works as the technology partner of Amsterdam University Press to produce multimedia editions (such as The bible in Dutch culture) and to digitise special collections and archives. In this way the Digital Library acts as a two-way street bringing in research from outside of the institution and distributing the research created in the institution externally (often adapting the material to produce richer, more usable products). Flexible publishing services which can adapt to the different needs of different subject areas with different publishing traditions can be used to support the institution's interest in e-science (as well as 'e-humanities' and 'e-social sciences'). 


\section{CONCLUSION}

Scholarly communication is in a state of flux. The way in which we purchase and access information is changing, more interest is being shown in the process by the funders of research, and our expectation of what we can do with data and research outputs is being expanded The use of the Internet as a communication channel has allowed us to fundamentally review what it is that we need and want from scholarly communications. More and more, we are concluding that a simple replication of the paper journal environment is insufficient. It is insufficient not only in that it needlessly limits access to the literature, but it also needlessly limits the imaginative new ways of using the literature and the data it contains. SPARC Europe is convinced that the greatest innovations in scholarly communications will occur in an open access environment. Access to the entire research corpus is only the beginning. New modes of research, new discovery tools, and new forms of scholarly communication are being developed. By unlocking the literature we can unlock the treasures contained within it for the increased efficiency of scientific research and the good of society as a whole.

\section{Acknowledgements}

This paper is based on five talks given during the SPARC Europe pre-conference seminar at the 2004 LIBER annual general meeting. Our thanks to LIBER for giving the pre-conference seminar over to SPARC Europe. I thank all the speakers at the seminar for their talks. This paper is the author's impression of those talks. While the speakers have helped to correct any gross misinterpretation of their talks, all impressions and conclusions drawn remain those of the author and should not be taken as being necessarily endorsed by the speakers.[4]

\section{NOTES}

1. See Mary Case's excellent history of SPARC for more details (Case, 2002).

2. See Peter Suber's list of cancelling libraries at http://www.earlham.edu/ peters/fos/lists.htm\#actions

3. Some background information about the UK e-Science Programme, see: http://www.rcuk.ac.uk/escience/

4. All the presentations can be found at http://www.sparceurope.org/Diary/LIBER\%20pre-conference.html 


\section{REFERENCES}

Case, Mary: "Igniting Change in Scholarly Communication: SPARC, Its Past, Present, and Future". Advances in Librarianship, Vol.26, 2002, 25 p.

http://www.arl.org/sparc/pubs/docs/SPARC_advances.pdf

Lynch, C.: "Digital Collections, Digital Libraries and the Digitization of Cultural Heritage Information". First Monday, 7(2002)5.

http://www.firstmonday.dk/issues/issue7_5/lynch/

Kircz, J.: E-based Humanities and E-humanities on a SURF platform, SURF (2004), 36 p. http://dare.uva.nl/en/record/119979

Prosser, David C.: "Between a rock and a hard place: the big squeeze for small publishers". Learned Publishing, 17(2004), 17-22.

http://eprints.rclis.org/archive/00000945/)

Scientific Publications: Free for All? London, The Stationery Office Limited, 2004, 118 p. http://www.publications.parliament.uk/pa/cm200304/cmselect/cmsctech/399/399.pdf

Swan, A.P and S.N. Brown: JISC/OSI, Journal Authors Survey Report (2004), 80 p. http://www.jisc.ac.uk/uploaded_documents/JISCOAreport1.pdf

\section{WEB SITES REFERRED TO IN THE TEXT}

arXiv .org e-Print archive. http://arxiv.org/

ARL - Association of Research Libraries. http://www.arl.org/

Berlin Declaration on Open Access to Knowledge in the Sciences and Humanities. http://www.zim.mpg.de/openaccess-berlin/berlindeclaration.html

Bible in Dutch culture $=$ De bijbel in de Nederlandse cultuur. http://www.bijbelencultuur.nl/

BioOne. http://www.bioone.org/

BOAI - Budapest Open Access Initiative. http://www.soros.org/openaccess/index.shtml

DARE - Digital Academic Repositories. http://www.darenet.nl/en/toon

DARE of the Universiteit van Amsterdam. http://dare.uva.nl/en

FAIR - Focus on Access to Institutional Resources Programme. http://www.jisc.ac.uk/index.cfm?name=programme_fair

Google. http://www.google.com/ 
JISC - Joint Information Systems Committee. http://www.jisc.ac.uk/

Living ReviewsOnline-only refereed review journals. http://www.livingreviews.org/ MPG - Max Planck Gesellschaft. http://www.mpg.de/portal/index.html

NIH - National Institutes of Health. http:/www.nih.gov/

Project Euclid. http://projecteuclid.org/Dienst/UI/1.0/Home

Project MUSE. http://muse.jhu.edu/

PubMedCentral. http://www.pubmedcentral.nih.gov/

OAI - Open Archives Initiative. http://www.openarchives.org/

OAIster. http://oaister.umdl.umich.edu/o/oaister

Queensland University of Technology E-print repository policy. http://www.qut.edu.au/admin/mopp/F/F_01_03.html

RoMEO Project (Rights MEtadata for Open archiving). http://www.lboro.ac.uk/departments/ls/disresearch/romeo/

SHERPA. http://www.sherpa.ac.uk/

SPARC, the Scholarly Publishing and Academic Resources Coalition. http://www.arl.org/sparc/

SPARC Europe. http://www.sparceurope.org/ 